AMUI, Gustavo Araújo; GUIMARÃES, Fernanda Albernaz do Nascimento (2016). Música na educação básica: referenciais teóricos de periódicos nacionais publicados entre 2000 e 2010. Per Musi. Ed. por Fausto Borém, Eduardo Rosse e Débora Borburema. Belo Horizonte: UFMG, n.34, p.89-112.

DOI: $10.1590 /$ permusi20163404

ARTIGO CIENTÍFICO

\title{
Música na educação básica: referenciais teóricos de periódicos nacionais publicados entre 2000 e 2010
}

\author{
Music in Elementary Education: National Journal References Published \\ between 2000 and 2010 in Brazil
}

\author{
Gustavo Araújo Amui \\ Universidade Federal de Goiás, Goiânia, Goiás, Brasil. \\ gustavoamui@yahoo.com.br
}

\author{
Fernanda Albernaz do Nascimento Guimarães \\ Universidade Federal de Goiás, Goiânia, Goiás, Brasil. \\ albernaz.fn@gmail.com
}

\begin{abstract}
Resumo: Este artigo apresenta resultados de pesquisa desenvolvida no Programa de Pós-Graduação em Música da Universidade Federal de Goiás, cujo objetivo foi identificar e analisar concepções que fundamentam o pensamento vigente em publicações de periódicos nacionais sobre educação musical na educação básica entre os anos de 2000 a 2010. 0 pensamento complexo na perspectiva de Edgar Morin e os conceitos de linguagem de Mikhail Bakhtin complementam o referencial teórico da pesquisa. Sendo assim, trazemos neste artigo dados e reflexões a partir de resultados obtidos na pesquisa, principalmente no que se refere aos referenciais teóricos dos artigos analisados. Dentre os resultados, observa-se que a área da educação musical no campo da educação básica dialoga com outras áreas e campos do conhecimento na construção de referenciais teóricos para a discussão de suas especificidades no contexto da educação básica, dados que corroboram os resultados de outras pesquisas. Constata-se que em alguns artigos, tomam-se autores da respectiva área (educação musical) como centrais em suas discussões. Observa-se, também, que as leis e os documentos normativos integram e tematizam o discurso sobre educação musical na educação básica.
\end{abstract}

Palavras-chave: educação musical na Educação Básica; educação em periódicos de música entre 2000 e 2010.

Abstract: This article bring out results of a masters' research developed in the Post Graduation Program in Music at the Universidade Federal de Goiás (Federal University of Goiás), which goal was to identify and analyze the concepts that underlie the prevailing thought in publications in national journals about music education in basic education from 2000 to 2010. The complex thinking from the perspective of Edgar Morin and the language concepts of Mikhail Bakhtin complements the theoretical referece from the research. Therefore, we bring in this article data and reflections from the results obtained in the research, with focus on the theoretical references from the analyzed articles. Among the results, it is observed that the area of music education in the field of basic education interacts with other areas and 
AMUI, Gustavo Araújo; GUIMARÃES, Fernanda Albernaz do Nascimento (2016). Música na educação básica: referenciais teóricos de periódicos nacionais publicados entre 2000 e 2010. Per Musi. Ed. por Fausto Borém, Eduardo Rosse e Débora Borburema. Belo Horizonte: UFMG, n.34, p.89-112.

fields of knowledge in the construction of theoretical references for the discussion of its particularities in the context of basic education, data that corroborates to the results of other researches. It is noted that in some aticles, authors from specific area (musical education) are taken as central in their discussions. It is also noted, that laws and regulatory documents compose and thematize the speech about musical education in basic education.

Keywords: musical education in Brazilian elementary school; education in music journals between 2000 and 2010.

Data de recebimento: 03/02/2016

Data de aprovação final: 02/04/2016

\section{1 - Introdução}

A educação básica é um dos diversos contextos de estudo e prática da educação musical no Brasil e que integra o currículo dos cursos de licenciatura em música. Sendo assim, os esforços dos profissionais da área da educação musical para sua sólida inclusão na educação básica são expressivos. Congressos anuais realizados nas universidades de diferentes regiões do país, pesquisas acadêmicas, publicações de livros e artigos sobre o tema, mobilizações de professores frente às decisões políticas quanto ao ensino de música e arte nas escolas, entre outras, são algumas das ações nas quais se evidencia a investidura dos profissionais para a construção de uma educação musical coerente com a formação de estudantes no contexto da educação básica.

A educação musical escolar traz, pela sua complexidade, uma diversidade de temáticas que necessariamente são observadas de forma relacional e complementar, tais como currículo, leis e documentos normativos, formação de professores, educação infantil, avaliação, criação, entre outros. Nessas temáticas, surgem questionamentos e reflexões acerca do fazer musical na escola que ampliam as possibilidades de entendimento e transmissão do conhecimento musical, o que exige do professor de música uma certa abertura para a diversidade de culturas e expressões próprias desse contexto.

Buscando melhor compreender essa complexa teia de relações que permeia a educação musical escolar, surgiu a necessidade de pesquisar sobre as concepções que 
AMUI, Gustavo Araújo; GUIMARÃES, Fernanda Albernaz do Nascimento (2016). Música na educação básica: referenciais teóricos de periódicos nacionais publicados entre 2000 e 2010. Per Musi. Ed. por Fausto Borém, Eduardo Rosse e Débora Borburema. Belo Horizonte: UFMG, n.34, p.89-112.

fundamentam propostas para o desenvolvimento da música na sala de aula, no sentido de que a reflexão sobre tais concepções ampliaria o entendimento e a superação de conflitos próprios da atuação como professor de música no ensino fundamental. Entende-se que tão importante quanto o professor aplicar uma proposta ou matriz curricular é ele ter a consciência das concepções filosóficas, paradigmáticas e epistemológicas que sustentam determinada proposta. De acordo com a Lei n. 11.769/08, “a música deverá ser conteúdo obrigatório, mas não exclusivo, de componente curricular [ensino da arte]" (BRASIL, 2008). Portanto, torna-se importante o esclarecimento dos conceitos sobre educação musical para toda a comunidade escolar (professores, alunos, funcionários, grupos gestores, equipes pedagógicas), porque "o momento atual é realmente o de pensar em maneiras de implementar a música na escola" (SEBBEN; SUBTIL, 2010, p.56).

Assim se desenvolveu a pesquisa de mestrado intitulada "Educação musical na educação básica: análise de artigos publicados em periódicos", na qual identificamos as concepções que fundamentam o pensamento vigente especificamente nas publicações sobre educação musical na educação básica. Para tanto, foi realizado um levantamento bibliográfico de periódicos científicos nacionais ativos e com publicações no período de 2000 a 2010, respeitando os seguintes critérios: a revista deveria ser reconhecida pela CAPES; a revista não poderia agrupar artigos com temas de uma única subárea da música, como, por exemplo, revistas específicas de musicologia e cognição, a exceção de revistas específicas de educação musical, como a Revista da $\mathrm{ABEM}$, que traz discussões diretamente relacionadas à temática proposta; por fim, a revista deveria ser específica de música e estar vinculada a algum programa de Pós-Graduação em Música do Brasil. Três exceções foram consideradas para este último critério: a Revista Opus (periódico da ANPPOM), Revista da ABEM e Revista Música na Educação Básica (ABEM). Essas revistas não estão diretamente vinculadas a Programas de Pós-Graduação em Música, mas são periódicos significativos para a pesquisa, o desenvolvimento e a divulgação da discussão sobre educação musical escolar. 
AMUI, Gustavo Araújo; GUIMARÃES, Fernanda Albernaz do Nascimento (2016). Música na educação básica: referenciais teóricos de periódicos nacionais publicados entre 2000 e 2010. Per Musi. Ed. por Fausto Borém, Eduardo Rosse e Débora Borburema. Belo Horizonte: UFMG, n.34, p.89-112.

Os critérios para seleção dos periódicos foram estipulados pensando organizar um objeto de estudo que possibilitasse o acesso a discussões que nos dessem indícios dos fundamentos científicos e concepções da área da educação musical escolar, buscando chegar também a um corpus de análise para investigações de como está sendo construído o discurso sobre educação musical na educação básica. Obedecendo a tais critérios, foram identificados nove periódicos de música, que, juntamente com os outros três não vinculados a Programas de Pós-Graduação em música, totalizam 12 periódicos selecionados no levantamento bibliográfico, os quais apresentamos na sequência dos mais antigos aos mais recentes: Revista Opus (ANPPOM), Revista da ABEM, Em Pauta (UFRGS), Cadernos-Colóquio (UNIRIO), Ictus (UFBA), PerMusi (UFMG), Revista Debates (UNIRIO), Música Hodie (UFG), Claves (UFPB), Música em Contexto (UnB), Música em Perspectiva (UFPR), Música na Educação Básica (MEB). Após o percurso de seleção dos periódicos, iniciamos a busca e a identificação dos artigos, dentro das 12 revistas selecionadas, com enfoque na educação musical no campo da educação básica. Dentre os critérios elencados para a identificação de tais artigos, observamos a presença de termos como "educação musical”, "educação básica”, "educação escolar", "ensino fundamental”, "ensino médio", "ensino regular", "escola pública”, “escola”, “escola regular”, “Lei no 9.394/96” e “Lei no 11.769/08”, nos elementos pré-textuais (título, resumo e palavras-chave) dos artigos. Do total de 1125 artigos das 12 revistas selecionadas entre os períodos de 2000 a 2010, 157 apresentam enfoque na educação musical no campo da educação básica, o que equivale a 14\% do total. Destes, foram selecionados 51 artigos que integraram o corpus de análise da pesquisa.

O referencial teórico da pesquisa foi construído a partir dos princípios que fundamentam o pensamento complexo na perspectiva de Edgar Morin (2007; 2008a; 2008b; 2010) e dos conceitos de linguagem de Mikhail Bakhtin (2003). 0 caráter dialógico da linguagem e os conceitos de "enunciado" e "alternância dos sujeitos do discurso", trabalhados por Bakhtin, foram centrais na identificação e análise das concepções. 


\section{2 - Edgar Morin - Pensamento Complexo}

O pensamento complexo estrutura-se dentro das discussões e expectativas de mudança paradigmática e epistemológica na ciência, nas quais a subjetividade desponta como um conceito central nessa nova perspectiva paradigmática. Os princípios recursivo, dialógico e hologramático do pensamento complexo na leitura de Edgar Morin (2007; 2008a; 2008b; 2010) são os principais eixos de análise das concepções.

A dicotomia teoria/prática e os dualismos mente/corpo, razão/emoção, objetividade/subjetividade, objeto/sujeito são resultados da Ciência Moderna. Já o pensamento complexo faz uma leitura do pensamento cartesiano, apontando que, durante anos, o ensino esteve calcado no racionalismo e na objetividade, tendo como consequências formas reducionistas e fragmentadas de pensar, agir, organizar, o que gera metodologias de ensino também reducionistas e fragmentadas. 0 pensamento complexo busca então a superação dessas dicotomias com uma maneira de se pensar os fenômenos de forma inseparáveis, visando a uma formação do ser humano a partir de práticas de ensino globalizantes e coerentes com sua vida e seu cotidiano.

Observa-se que os princípios do pensamento complexo possibilitam o pensar sobre educação musical escolar dentro de uma perspectiva coerente com a mudança paradigmática na educação e com a reflexão sobre a construção e o desenvolvimento da educação musical nas escolas.

Alguns autores da educação baseiam-se no pensamento complexo para refletir sobre o contexto da educação básica e propor possibilidades de ação do professor frente às diversidades desse contexto. Akiko Santos (2003), por exemplo, no livro Didática sob a Ótica do Pensamento Complexo, faz importantes reflexões sobre o conceito de subjetividade na perspectiva da complexidade na educação escolar.

Os aspectos subjetivos da aprendizagem são subestimados. As técnicas didáticas e os planos de aula formalizam a atividade docente, burocratizando a prática do dia a dia, abstraindo seus fundamentos. Os 
AMUI, Gustavo Araújo; GUIMARÃES, Fernanda Albernaz do Nascimento (2016). Música na educação básica: referenciais teóricos de periódicos nacionais publicados entre 2000 e 2010. Per Musi. Ed. por Fausto Borém, Eduardo Rosse e Débora Borburema. Belo Horizonte: UFMG, n.34, p.89-112.

\author{
questionamentos disponibilizados pelas disciplinas teóricas, \\ ministradas no início do curso, não são retomados ao final para exercer \\ a sua função crítica nas disciplinas de práticas de ensino, legitimando \\ a dicotomia teoria/prática (SANTOS, 2003, p.34).
}

Edgar Morin apresenta o pensamento complexo e reflete sobre as formas de organização e estruturas escolares, observa as relações entre professores, alunos, diretores e demais membros da comunidade escolar, considerando a escola como um espaço que agrega as várias expressões da cultura e da sociedade. Isso porque, para ele, a escola é uma parte da comunidade que retém e agrega as multiplicidades e diversidades de culturas, de relações, um local que concentra as diferentes esferas da sociedade, permitindo assim uma experiência social globalizada. Edgar Morin considera que as ações pedagógicas podem tanto incentivar o pensamento globalizante e integrado nos estudantes em formação quanto delimitar e podar o raciocínio integrado do estudante em detrimento de aprendizados e conteúdos objetivos e pouco criativos, com ideias fragmentadas e limitadas (MORIN, 2008a). No livro A cabeça bemfeita, o autor entende que a escola é o espaço que possibilita a transformação social através de uma reforma no pensamento.

\title{
3 - Mikhail Bakhtin e os conceitos de linguagem
}

Em Mikhail Bakhtin (2003), temos o enunciado como um conceito central no entendimento do caráter dialógico da linguagem, uma vez que "o emprego da língua efetua-se em forma de enunciados (orais e escritos) concretos e únicos, proferidos pelos integrantes desse ou daquele campo da atividade humana" (BAKHTIN, 2003, p.261). Temos assim uma primeira definição do objeto da pesquisa, que são os enunciados escritos em forma de artigos publicados em periódicos científicos, e o campo da atividade humana em questão é a educação musical, mais especificamente a educação musical no contexto da educação básica.

Na teoria bakhtiniana, o conceito de enunciado compreende expressões escritas e orais. No entanto, em virtude das características da pesquisa, trabalhou-se o conceito de 
AMUI, Gustavo Araújo; GUIMARÃES, Fernanda Albernaz do Nascimento (2016). Música na educação básica: referenciais teóricos de periódicos nacionais publicados entre 2000 e 2010. Per Musi. Ed. por Fausto Borém, Eduardo Rosse e Débora Borburema. Belo Horizonte: UFMG, n.34, p.89-112.

enunciado voltado para a forma escrita, entendendo que essa forma engloba não só a dimensão verbal como também a social:

\begin{abstract}
Desse modo, considerando a dimensão social como parte constitutiva do enunciado, este tem autor e destinatário, tem uma finalidade discursiva, está ligado a uma situação de interação, dentro de uma dada esfera social, entre outros aspectos. A situação de interação não é um elemento externo (contextual); ela se integra ao enunciado, constituindo-se como uma das suas dimensões constitutivas, indispensáveis para a compreensão do sentido do enunciado (RODRIGUES, 2004, p.424).
\end{abstract}

No conceito de enunciado, tem-se a ideia de alternância dos sujeitos do discurso, pois quem fala ou profere algo diz dentro de um percurso histórico, de uma tradição filosófica, trazendo, em sua fala, mesmo que de forma inconsciente, feixes de expressões e de vozes que construíram e repassaram discursos, valores, ideias e concepções. A ideia de alternância dos sujeitos do discurso entende que, na fala de um determinado autor, observando suas concepções, podemos ter indícios de influências e representações das ideias e discursos de outros autores, sejam eles contemporâneos ou não, ou mesmo de diferentes filosofias que se construíram ao longo do tempo:

\footnotetext{
[...] em qualquer enunciado, quando estudado com mais profundidade em situações concretas de comunicação discursiva, descobrimos toda uma série de palavras do outro semilatentes e latentes, de diferentes graus de alteridade. Por isso o enunciado é representado por ecos como que distantes e mal percebidos das alternâncias dos sujeitos do discurso e pelas tonalidades dialógicas, enfraquecidas ao extremo pelos limites dos enunciados, totalmente permeáveis à expressão do autor (BAKHTIN, 2003, p.299).
}

O conceito de enunciado, na obra de Bakhtin, traz toda essa complexa relação de alternância dos sujeitos do discurso em um constante movimento dialógico, como um elo ininterrupto entre múltiplos tempos que se concretiza na linguagem. Desse modo, "cada palavra é como que o resultado de uma relação de força entre o eu e o outro, numa tensão que se manifesta em todos os níveis, no 'material', na 'forma', no 'conteúdo', num todo inseparável” (TEZZA, 1988, p.55).

É nessa perspectiva que se identificam os enunciados escritos em forma de artigos de periódicos para análise do discurso sobre educação musical na educação básica. Procuramos, assim, elucidar os elos implícitos e explícitos nas concepções dos autores. 
AMUI, Gustavo Araújo; GUIMARÃES, Fernanda Albernaz do Nascimento (2016). Música na educação básica: referenciais teóricos de periódicos nacionais publicados entre 2000 e 2010. Per Musi. Ed. por Fausto Borém, Eduardo Rosse e Débora Borburema. Belo Horizonte: UFMG, n.34, p.89-112.

Como o objeto e os objetivos da pesquisa desenvolvida estão diretamente ligados aos conceitos de linguagem trabalhados por Bakhtin, é a realidade dialógica da linguagem que nos permitiu analisar artigos científicos de periódicos escritos entre os anos de 2000 a 2010, com a intenção de identificar e refletir sobre as concepções que fundamentam o pensamento vigente em publicações recentes sobre educação musical na educação básica, ainda que estas estejam fundamentadas em concepções do século XVI, por exemplo. As concepções mais recentes estão, de alguma forma, interligadas com antigas concepções filosóficas, visto que fazem uso de toda a tradição filosófica em seus fundamentos.

\section{4 - Referenciais teóricos no discurso sobre educação musical escolar}

Observados os princípios do pensamento complexo (Edgar Morin) e os conceitos de linguagem em Bakhtin, apresentaremos, neste artigo, reflexões que buscam responder duas das quatro questões que nortearam a pesquisa: Quem são os emissores, os falantes, os sujeitos do discurso sobre educação musical na educação básica? 0 campo da música na educação básica acompanha ou faz alguma referência à mudança paradigmática observada por Edgar Morin e outros pensadores?

Para responder a primeira pergunta, retomamos os conceitos de linguagem em Bakhtin: o caráter dialógico da linguagem; os múltiplos falantes dentro de determinado enunciado; a ideia de alternância dos sujeitos do discurso. Logo, foram observados dois itens nos artigos: 1) as referências às leis e aos documentos que regem a educação, por considerá-los que são importantes na identificação e caracterização dos sujeitos do discurso sobre educação musical na educação básica; 2) o referencial teórico de cada artigo, mediante o qual se buscaram os autores centrais em cada discussão. Os autores, as leis e os documentos referenciados foram observados no corpo do texto e não nas referências bibliográficas. Sendo assim, o quadro da Figura 1 abaixo apresenta os dados coletados, em cada artigo, referentes aos dois itens. Em seguida, comparamos tais dados com os resultados de pesquisa desenvolvida por Oliveira et al (2012), que 
AMUI, Gustavo Araújo; GUIMARÃES, Fernanda Albernaz do Nascimento (2016). Música na educação básica: referenciais teóricos de periódicos nacionais publicados entre 2000 e 2010. Per Musi. Ed. por Fausto Borém, Eduardo Rosse e Débora Borburema. Belo Horizonte: UFMG, n.34, p.89-112.

buscou o mapeamento das "referências utilizadas em parte da produção científica brasileira sobre educação musical escolar" (OLIVEIRA et al, 2012, p.1879).

\begin{tabular}{|c|c|c|}
\hline Artigo & $\begin{array}{l}\text { Documentos normativos } \\
\text { referenciados }\end{array}$ & $\begin{array}{l}\text { Autores centrais no } \\
\text { referencial teórico }\end{array}$ \\
\hline (DUARTE, 2001) & -- & $\begin{array}{c}\text { S. Moscovici; } \\
\text { A. J. Alves-Mazzotti. }\end{array}$ \\
\hline (DANTAS, 2001) & -- & Giles Deleuze; Felix Guattari \\
\hline (SANTOS, 2001) & Lei n. 9.394/96 & Jaques-Dalcroze \\
\hline (DEL BEN, 2001) & -- & $\begin{array}{c}\text { Alfred Schutz; Jussamara } \\
\text { Souza; Rudolf-Dieter Kraemer; } \\
\text { José Gimeno Sacristán }\end{array}$ \\
\hline $\begin{array}{l}\text { (FERNANDES, } \\
\text { 2001) }\end{array}$ & $\begin{array}{c}\text { Lei n. 5.692/71, Parecer 4873/75, } \\
\text { Parecer 672/69, PCN para o ensino } \\
\text { fundamental }\end{array}$ & -- \\
\hline (BEINEKE, 2001) & -- & $\begin{array}{l}\text { Freema Elbaz; Donald A. } \\
\text { Schon }\end{array}$ \\
\hline (PENNA, 2002) & $\begin{array}{c}\text { Lei n. 9.394/96, 5.692/71, PCN para o } \\
\text { ensino fundamental e PCN para o } \\
\text { ensino médio }\end{array}$ & -- \\
\hline (DEL BEN, 2002) & -- & A. Schutz \\
\hline $\begin{array}{l}\text { (WEICHSELBAUM, } \\
\text { 2002) }\end{array}$ & -- & $\begin{array}{l}\text { Pedro Demo; J. Gimeno } \\
\text { Sacristán e William Doll Jr; } \\
\text { Keith Swanwick }\end{array}$ \\
\hline (ARROYO, 2002) & $\begin{array}{l}\text { PCN para 3o e 4⿳o ciclos do ensino } \\
\text { fundamental e PCN para a Educação } \\
\text { Infantil }\end{array}$ & Ruth Finnegan \\
\hline $\begin{array}{c}\text { (DUARTE; } \\
\text { MAZZOTTI, 2002) }\end{array}$ & -- & Jean Jacques Nattiez \\
\hline (PENNA, 2003) & $\begin{array}{c}\text { Lei n. 5.692/71, Lei n. 9.394/96, PCN } \\
\text { para o ensino fundamental }\end{array}$ & -- \\
\hline (MATEIRO, 2003) & -- & $\begin{array}{l}\text { A. Pérez Gómez, D. A. Schon; K. } \\
\text { M. Zeichner }\end{array}$ \\
\hline (SOUZA et al, 2003): & -- & -- \\
\hline (BELLOCHIO, 2003) & $\begin{array}{c}\text { Lei n. 9.394/96, Cita Diretrizes } \\
\text { Curriculares Nacionais para a } \\
\text { Formação de Professores da Educação } \\
\text { Básica }\end{array}$ & -- \\
\hline (GOMES, 2003) & -- & Cláudia Bellochio \\
\hline (PENNA, 2004) & $\begin{array}{c}\text { Lei n. 4.024/61, Lei n. 5.692/71, Lei n. } \\
\text { 9.394/96, PCN para o ensino } \\
\text { fundamental e médio, PCN para a }\end{array}$ & $\begin{array}{c}\text { Bárbara Freitag e Dermeval } \\
\text { Saviani }\end{array}$ \\
\hline
\end{tabular}


AMUI, Gustavo Araújo; GUIMARÃES, Fernanda Albernaz do Nascimento (2016). Música na educação básica: referenciais teóricos de periódicos nacionais publicados entre 2000 e 2010. Per Musi. Ed. por Fausto Borém, Eduardo Rosse e Débora Borburema. Belo Horizonte: UFMG, n.34, p.89-112.

\begin{tabular}{|c|c|c|}
\hline & $\begin{array}{c}\text { educação infantil, Parecer CFE n⿳o } \\
\text { 1.284/73 e Resolução CFE n⿳0 23/73 } \\
\text { (termos normativos acerca do curso } \\
\text { de Educação Artística), Parecer nº } \\
540 / 77\end{array}$ & \\
\hline (SOUZA, 2004) & $\begin{array}{c}\text { Diretrizes Curriculares Nacionais, PCN, } \\
\text { Lei n. } 9.394 / 96\end{array}$ & -- \\
\hline (VIEIRA et al, 2004) & -- & -- \\
\hline (ARROYO, 2004) & $\begin{array}{l}\text { Lei n. } 9.394 / 96 \text {, Lei n. } 5.692 / 71 \text {, cita } \\
\text { boletim informativo da ABEM }\end{array}$ & Maura Penna \\
\hline $\begin{array}{l}\text { (FERNANDES, } \\
\text { 2004) }\end{array}$ & $\begin{array}{c}\text { Lei n. 9.394/96, Lei n. 5.692/71, PCN } \\
\text { para o ensino fundamental, PCN-Artes, } \\
\text { Referencial Curricular Nacional da } \\
\text { Educação Infantil (RCNEI), a } \\
\text { Constituição Nacional, uma série de } \\
\text { documentos (currículos) estaduais e } \\
\text { municipais }\end{array}$ & $\begin{array}{l}\text { Maura Penna; } \\
\text { Keith Swanwick }\end{array}$ \\
\hline $\begin{array}{l}\text { (FERNANDES, } \\
\text { 2005) }\end{array}$ & $\begin{array}{l}\text { Lei n. 9394/96, PCN-Arte para o } \\
\text { ensino fundamental, EJA, Proposta } \\
\text { Curricular para o 2º Segmento da } \\
\text { Educação de Jovens e Adultos, cita } \\
\text { outros documentos nacionais e } \\
\text { municipais para a educação, como a } \\
\text { Resolução no 314, de } 1988\end{array}$ & Álvaro Vieira Pinto \\
\hline (DEL BEN, 2005) & $\begin{array}{c}\text { Lei n. } 5.692 / 71 \text {, Lei n. 9.394/96, PCN } \\
\text { para o ensino fundamental }\end{array}$ & $\begin{array}{c}\text { Liane Hentschke; A. Oliveira; } \\
\text { Maura Penna }\end{array}$ \\
\hline (ÁLVARES, 2005) & $\begin{array}{c}\text { Lei n. 9.394/96, cita Parâmetros } \\
\text { Curriculares Nacionais e Diretrizes } \\
\text { Curriculares Nacionais }\end{array}$ & -- \\
\hline $\begin{array}{c}\text { (SPANAVELLO; } \\
\text { BELLOCHIO, 2005) }\end{array}$ & PCN, Lei n. 9.394/96 & Cláudia Ribeiro Bellochio \\
\hline (ARROYO, 2005) & Lei n. 9.394/96 & Tia DeNora \\
\hline (SILVA, 2006) & -- & $\begin{array}{l}\text { Lucy Green; Joan Scott; } \\
\text { Guacira L. Louro }\end{array}$ \\
\hline (FRANÇA, 2006) & Lei n. 5.692/71, LDB 9.394/96 & Keith Swanwick; Paddy Walsh \\
\hline $\begin{array}{l}\text { (FUCCI-AMATO, } \\
\text { 2006) }\end{array}$ & $\begin{array}{l}\text { Lei n. 4024/61, Lei n. 5.692/71, Lei n. } \\
\text { 9.394/96, PCN, decreto federal de } \\
1854\end{array}$ & -- \\
\hline (OLIVEIRA, 2006) & -- & Keith Swanwick \\
\hline (SANTOS, 2006) & Lei n. 9.394/96, PCN-Artes & -- \\
\hline (BUSTOS, 2007) & -- & Jean Piaget \\
\hline (FERREIRA, 2007) & $\begin{array}{l}\text { Referencial Curricular Nacional para a } \\
\text { Educação Infantil }\end{array}$ & Pedro Bloch \\
\hline
\end{tabular}


AMUI, Gustavo Araújo; GUIMARÃES, Fernanda Albernaz do Nascimento (2016). Música na educação básica: referenciais teóricos de periódicos nacionais publicados entre 2000 e 2010. Per Musi. Ed. por Fausto Borém, Eduardo Rosse e Débora Borburema. Belo Horizonte: UFMG, n.34, p.89-112.

\begin{tabular}{|c|c|c|}
\hline $\begin{array}{c}\text { (QUEIROZ; } \\
\text { MARINHO, 2007) }\end{array}$ & $\begin{array}{l}\text { Lei n. 4.024/61, Lei n. } 5.692 \text { de 1971, } \\
\text { Lei n. 9.394/96, PCN }\end{array}$ & -- \\
\hline (BARBOSA, 2007) & $\begin{array}{l}\text { Referencial Curricular Nacional para a } \\
\text { Educação Infantil (RCNEI) }\end{array}$ & $\begin{array}{l}\text { Dermeval Saviani; Lev } \\
\text { Vigostki }\end{array}$ \\
\hline $\begin{array}{c}\text { (BELLOCHIO; } \\
\text { BEINEKE, 2007) }\end{array}$ & $\begin{array}{c}\text { Diretrizes Curriculares para a } \\
\text { Formação de Professores da Educação } \\
\text { Básica }\end{array}$ & Donald A. Schön \\
\hline (PENNA, 2008) & $\begin{array}{l}\text { Lei n. 9.394/96, Lei n. 5.692/71, faz } \\
\text { referência ao projeto de lei do Senado } \\
\text { no } 330 \text {, de } 2006\end{array}$ & -- \\
\hline $\begin{array}{l}\text { (FUCCI-AMATO; } \\
\text { CARLINI, 2008) }\end{array}$ & Lei n. 11.769/08 & -- \\
\hline (COSTA, 2008) & -- & -- \\
\hline (SOUZA, 2008) & -- & -- \\
\hline $\begin{array}{l}\text { (LIMA; TRAJANO, } \\
\text { 2008) }\end{array}$ & $\begin{array}{c}\text { Lei 11.769/08, PCN-Artes, LDB } \\
5.692 / 71, \text { LDB 9394/96 }\end{array}$ & Howard Gardner; Eliane Leão \\
\hline $\begin{array}{c}\text { (BARBOSA; } \\
\text { FRANÇA, 2009) }\end{array}$ & -- & Keith Swanwick \\
\hline $\begin{array}{l}\text { (COUTO; SANTOS, } \\
\text { 2009) }\end{array}$ & Lei n. 11.769/08 & $\begin{array}{c}\text { Keith Swanwick; Liane } \\
\text { Hentschke; Maura Penna }\end{array}$ \\
\hline (CERQUEIRA, 2009) & Lei n. $11.769 / 08$ e Lei n. 5.692/71 & Maria Isabel Montandon \\
\hline (AZEVEDO, 2009) & Lei n. 9.394/96, Lei n. 11.769/08 & Bernard Charlot \\
\hline (CASTRO, 2009) & $\begin{array}{l}\text { Lei n. 11.769/08, PCN-Artes, Decreto } \\
\text { Federal no } 630 \text { de 1851, Decreto } \\
\text { Federal no } 1.331 \text { A de 1854, Decreto no } \\
981 \text { de 1890, Decreto no } 19.890 \text { de } \\
\text { 1931, Lei n. 4.024 de 1961, Lei n. } 5.692 \\
\text { de 1971, Lei n. 9.934/96 }\end{array}$ & -- \\
\hline $\begin{array}{l}\text { (SEBBEN; SUBTIL, } \\
\text { 2010) }\end{array}$ & $\begin{array}{l}\text { Lei n. 5.692/71, Lei n. } 11.769 / 08 \text {, Lei } \\
\text { n. } 11.274 / 06\end{array}$ & Eco e Merriam \\
\hline $\begin{array}{l}\text { (BENEDETTI; KERR, } \\
\text { 2010) }\end{array}$ & -- & N. Duarte; Dermeval Saviani \\
\hline $\begin{array}{c}\text { (QUEIROZ; } \\
\text { MARINHO, 2010) }\end{array}$ & $\begin{array}{c}\text { Cita documentos do Ministério da } \\
\text { Educação, Resolução nº 009/2006, Lei } \\
\text { n. 11.274, sobre a mudança de } \\
\text { estrutura do ensino fundamental de } 8 \\
\text { para } 9 \text { anos }\end{array}$ & -- \\
\hline $\begin{array}{l}\text { (CUERV0; PEDRINI, } \\
\text { 2010) }\end{array}$ & -- & -- \\
\hline (FRANÇA, 2010) & PCN & -- \\
\hline
\end{tabular}

Figura 1: Quadro de documentos normativos e autores centrais no referencial teórico FONTE: Dados extraídos a partir da leitura integral dos 51 artigos que integram o corpus de análise da pesquisa. 
AMUI, Gustavo Araújo; GUIMARÃES, Fernanda Albernaz do Nascimento (2016). Música na educação básica: referenciais teóricos de periódicos nacionais publicados entre 2000 e 2010. Per Musi. Ed. por Fausto Borém, Eduardo Rosse e Débora Borburema. Belo Horizonte: UFMG, n.34, p.89-112.

NOTA: A primeira coluna apresenta o sobrenome que indica o(s) autor(es) do artigo analisado e o ano. A segunda coluna apresenta os documentos referenciados nos elementos textuais de cada artigo. Já a terceira coluna apresenta o(s) autor(es) central(is) no referencial teórico.

Ao observar, especificamente, o item 1, "Referências às leis e aos documentos que regem a educação", chega-se aos seguintes resultados: do total de artigos analisados, 32 mencionam alguma Lei, ou documento, que rege a educação, o que equivale a $62,8 \%$ do total, e 19 (37,2\%) não mencionam Lei, ou documento, que rege a educação. Os dados revelam que tais documentos normativos não são utilizados por todos os autores em seus discursos, mas pela maioria deles. Concluímos, com a ênfase dada a esses documentos nos 32 artigos, em que eles estão presentes, que as leis e os documentos, norteadores da educação, são enunciados escritos que caracterizam, integram e tematizam o discurso sobre educação musical na educação básica, ou seja, as ações políticas expressas em legislações educacionais estão presentes nas vozes (polifonia) do discurso sobre educação musical escolar em artigos de periódicos. Observa-se que tais dados corroboram com os resultados de uma pesquisa desenvolvida por Oliveira et al (2012), do Grupo "Música e Escola”, coordenado por Luciana Del Ben. Os autores evidenciam que existe uma presença expressiva de documentos normativos mencionados nos artigos analisados e afirmam:

\footnotetext{
A presença expressiva de documentos oficiais (normativos e norteadores) pode ser justificada pela preocupação da área com a regulamentação e institucionalização da educação musical escolar, mas não necessariamente por possíveis contribuições conceituais trazidas por esses documentos (OLIVEIRA et al, 2012, p.1882).
}

Dentre os artigos integrantes do corpus de análise, três publicados pela Revista da ABEM, em 2004, discutem a legislação educacional referente à música de forma central e detalhada (ARROYO, 2004; FERNANDES, 2004; PENNA, 2004). Os demais artigos não fazem uma discussão central da legislação educacional, mas utilizam-na de forma a introduzirem ou contextualizarem determinadas temáticas sobre educação musical na educação básica. Dentre as leis, a LDB n. 9.394/96 (BRASIL, 1996) é o documento mais mencionado nos artigos, sendo referenciada em 20 artigos dos 51 analisados. Considerando as referências à Lei n.11.769/08 (BRASIL, 2008), que altera a LDB n. 9.394/96, o número passa de 20 para 24 artigos que referenciam a LDB n. 9.394/96. A 
AMUI, Gustavo Araújo; GUIMARÃES, Fernanda Albernaz do Nascimento (2016). Música na educação básica: referenciais teóricos de periódicos nacionais publicados entre 2000 e 2010. Per Musi. Ed. por Fausto Borém, Eduardo Rosse e Débora Borburema. Belo Horizonte: UFMG, n.34, p.89-112.

LDB n. 5.692/71 (BRASIL, 1971), apesar de não ser a lei vigente desde 1996, ainda é muito referenciada pelos autores: em 15 artigos. Os Parâmetros Curriculares Nacionais para o Ensino Fundamental (BRASIL, 1997) são mencionados em 14 artigos. 0 Referencial Curricular Nacional para a Educação Infantil (BRASIL, 1998) é referenciado em três artigos.

Observamos que dois artigos fazem referência, de forma equivocada, aos "Parâmetros Curriculares Nacionais para a Educação Infantil”, o que não é correto porque este documento não existe. 0 documento destinado à educação infantil é o RCNEI Referencial Curricular Nacional para a Educação Infantil. Isso demonstra certa imprecisão no discurso científico da área da educação musical, que reproduz informações referentes aos PCNs de forma equivocada.

Sobre o item 2, "Referencial teórico de cada artigo, buscando os autores centrais em cada discussão", não foi possível, em alguns artigos, identificar os autores centrais no referencial teórico. Nesses casos, os autores dos artigos não se fundamentavam em um autor específico, ou em um pequeno grupo de autores, mas utilizavam uma grande quantidade de referenciais para embasar determinada temática ou discutiam as questões e tinham como referência as leis ou os documentos oficiais. Ressalta-se que diversos outros autores são referenciados nos artigos, que embasam diferentes temáticas. Os dados aqui apresentados não identificam todos os autores, as temáticas e os campos do conhecimento a que eles estão vinculados, mas, apenas, os autores centrais nas discussões.

Os dados indicam que a área correspondente à educação musical, no campo da educação básica, dialoga com diferentes áreas e campos do conhecimento. Em alguns casos, tomam-se autores da respectiva área (educação musical) como centrais em suas discussões. Esses dados também corroboram com a pesquisa de OLIVEIRA et al (2012), que não observou especificamente os autores centrais nos artigos, mas todos os autores referenciados (elementos pós-textuais). Apesar dessa diferenciação no que se refere à observação do objeto, podem-se apontar duas semelhanças nos resultados dos dados coletados nesta pesquisa com a pesquisa de OLIVEIRA et al (2012): 1 - dispersão 
AMUI, Gustavo Araújo; GUIMARÃES, Fernanda Albernaz do Nascimento (2016). Música na educação básica: referenciais teóricos de periódicos nacionais publicados entre 2000 e 2010. Per Musi. Ed. por Fausto Borém, Eduardo Rosse e Débora Borburema. Belo Horizonte: UFMG, n.34, p.89-112.

na produção que embasa as pesquisas sobre música na educação básica, ou seja, os autores de artigos científicos sobre música nas escolas não seguem uma linha ou área específica de conhecimento, mas buscam referenciais e autores de áreas e matrizes diversificadas do conhecimento, o que caracteriza a multidimensionalidade e a dispersão da área (OLIVEIRA et al, 2012, p.1885); 2 - a área dá sinais de autonomia em alguns temas ao tomar autores da educação musical como embasamento teórico, já que existe um "corpo de conhecimento construído pela própria área, que tem sido utilizado para orientar a produção sobre educação musical escolar" (OLIVEIRA et al, 2012, p.1885).

Outros cruzamentos podem ser feitos com a pesquisa de OLIVEIRA et al (2012), cujo corpus de análise foram 80 artigos publicados na Revista da ABEM, na década de 2000. Além de contemplar parte expressiva do objeto desta pesquisa, visto que os artigos da ABEM são maioria significativa, o período de análise na pesquisa de OLIVEIRA et al (2012) é paralelo ao desta pesquisa, o que nos permite maiores possibilidades de diálogos e comparações. Os pesquisadores são apresentados na tabela da Figura 2, a seguir, seguidos da frequência em que são referenciados. Destaca-se que não há uma distinção, na referida pesquisa, entre autores centrais no referencial teórico e demais referências na coleta dos dados. "Somando-se os autores, organizadores, editores e coordenadores dos materiais referenciados, o resultado é 1679 ocorrências, contadas as repetições" (OLIVEIRA et al, 2012, p.1880).

\begin{tabular}{|l|c|c|}
\hline \multicolumn{1}{|c|}{ Autor(a) } & Ocorrências & Percentual \\
\hline PENNA, M. L. F. & 102 & 5,5 \\
\hline SOUZA, J. V. & 48 & 2,6 \\
\hline BELLOCHIO, C. R. & 46 & 2,5 \\
\hline HENTSCHKE, L. & 39 & 2 \\
\hline FIGUEIREDO, S. L. F. & 36 & 1,8 \\
\hline SWANWICK, K. & 34 & 1,2 \\
\hline ARROYO, M. & 22 & 1,2 \\
\hline DUARTE, M. A. & 22 & \\
\hline
\end{tabular}


AMUI, Gustavo Araújo; GUIMARÃES, Fernanda Albernaz do Nascimento (2016). Música na educação básica: referenciais teóricos de periódicos nacionais publicados entre 2000 e 2010. Per Musi. Ed. por Fausto Borém, Eduardo Rosse e Débora Borburema. Belo Horizonte: UFMG, n.34, p.89-112.

\begin{tabular}{|l|c|c|}
\hline FRANÇA, M. C. C. & 21 & 1,1 \\
\hline DEL-BEN, L. M. & 19 & 1 \\
\hline OLIVEIRA, A. J. & 18 & 0,8 \\
\hline BEINEKE, V. & 15 & 0,8 \\
\hline FUKS, R. & 15 & -- \\
\hline 12 autores & 10 a 15 & -- \\
\hline 26 autores & 5 a 9 & -- \\
\hline 24 autores & 4 & -- \\
\hline 36 autores & 3 & $\mathbf{1 0 0}$ \\
\hline 93 autores & 2 & -- \\
\hline 463 autores & 1679 & \\
\hline Total & & \\
\hline
\end{tabular}

Figura 2: Frequência de autores referenciados.

Fonte: Construído por Mário André W. Oliveira et al (2012).

Ao comparar os dados a Figura 2 (frequência de autores referenciados) com os dados da Figura 1 (quadro com autores centrais no referencial teórico), observamos que seis autores da educação musical aparecem entre os 12 mais referenciados e também são utilizados como autores centrais no referencial teórico de alguns artigos: Maura Penna, Jusamara Souza, Cláudia Bellochio, Liane Hentschke, Keith Swanwick, Alda Oliveira. Maura Penna aparece como a autora mais referenciada nos artigos, considerando os autores de todas as áreas do conhecimento. Quanto aos dados sobre os autores centrais no referencial teórico (Figura 1), Keith Swanwick destaca-se como o autor mais recorrente, quando se considera apenas os autores da educação musical. 


\section{5 - A mudança paradigmática no pensamento dos autores que escrevem sobre educação musical na educação básica}

A segunda pergunta que propomos para reflexão neste artigo é a seguinte: o campo da música na educação básica acompanha ou faz alguma referência à mudança paradigmática observada por Edgar Morin e outros autores?

A maioria dos autores dos artigos científicos analisados apresenta concepções diversas, que estão coerentes com os princípios recursivo, dialógico e hologramático do pensamento complexo. Quando se trata de ações na sala de aula, das formas de organização no contexto escolar, suas estruturas e regras, dos termos normativos que regem a educação, os autores tendem a fazer leituras que apresentem tais estruturas como fenômenos que dificultam um trabalho de qualidade com a música. Nas críticas, observa-se que tais formas de organização estão coerentes com o pensamento dicotômico, de separação e fragmentação.

Os autores não só criticam as estruturas, mas também apresentam propostas e ações que podem possibilitar a superação dessas estruturas fragmentadas. Podemos dizer que os autores dos artigos científicos analisados tendem a acompanhar a mudança paradigmática apontada por Edgar Morin e outros autores. Porém, temos o cuidado de não direcionarmos essa afirmação ao campo da educação musical na educação básica, já que tal campo não se restringe apenas aos autores de artigos de periódicos, pois o campo compreende também professores que atuam na sala de aula, diretores, grupos gestores e equipes pedagógicas, entre outros. As formas de organização no contexto escolar e os documentos normativos, por exemplo, tendem a acompanhar o paradigma moderno. Entretanto, os enunciados escritos em forma de artigos podem modificar, reformar, transformar as formas de organização no contexto escolar. Assim, o campo da educação musical na educação básica não necessariamente acompanha, mas tende a estar coerente com a mudança paradigmática no sentido de que os enunciados escritos em artigos científicos podem interferir nessas organizações. 
AMUI, Gustavo Araújo; GUIMARÃES, Fernanda Albernaz do Nascimento (2016). Música na educação básica: referenciais teóricos de periódicos nacionais publicados entre 2000 e 2010. Per Musi. Ed. por Fausto Borém, Eduardo Rosse e Débora Borburema. Belo Horizonte: UFMG, n.34, p.89-112.

\section{6 - Considerações finais}

Acreditamos que os dados sobre a fundamentação teórica dos artigos analisados apresentam indícios de quem são os emissores, os sujeitos do discurso sobre educação musical na educação básica. Os dados da pesquisa revelam alguns nomes, tanto no quadro dos referenciais centrais quanto na tabela de autores mais referenciados, que são importantes para observarmos como a área da educação musical se constrói e se consolida como prática fundamental na educação básica. Maura Penna, Jusamara Souza, Cláudia Bellochio, Liane Hentschke, Keith Swanwick e Alda Oliveira são pesquisadores e educadores musicais que, através de seus enunciados escritos em artigos de periódicos, sejam eles de sua própria autoria ou referenciados por outros autores, ampliam e constroem os pilares que sustentam algumas das temáticas sobre educação musical escolar.

Nesta análise, não se considerou a legislação educacional como documentos que podem ser utilizados como centrais no referencial teórico de artigos científicos. Talvez se se considerasse essa especificidade, os resultados seriam diferentes. Provavelmente os documentos normativos seriam mais referenciados do que o autor mais buscado como referencial teórico central, Keith Swanwick.

Como vimos, além da multiplicidade, a área da educação musical também dá sinais de autonomia em alguns temas, tomando autores da própria área como embasamento teórico (OLIVEIRA et al, 2012). Inferimos então que a área da educação musical é construída em diálogo com outras áreas do conhecimento, como sociologia, filosofia, pedagogia, psicologia, antropologia, dentre outras, sem perder suas especificidades, ou seja, considera elementos e temáticas que são próprias da área e construídas por autores da educação musical em seu desenvolvimento.

As discussões dos dados apontam para um discurso sobre educação musical na educação básica que tende a acompanhar a mudança paradigmática observada e sustentada pelo pensamento complexo. A maioria dos autores apresenta, criticamente, 
AMUI, Gustavo Araújo; GUIMARÃES, Fernanda Albernaz do Nascimento (2016). Música na educação básica: referenciais teóricos de periódicos nacionais publicados entre 2000 e 2010. Per Musi. Ed. por Fausto Borém, Eduardo Rosse e Débora Borburema. Belo Horizonte: UFMG, n.34, p.89-112.

algumas formas de organização, possivelmente cartesianas, presentes no contexto escolar, que dificultam o desenvolvimento de propostas da educação musical que acompanham essas mudanças paradigmáticas na educação. Isso caracteriza uma tensão entre as concepções da maioria dos autores, que estariam coerentes com a mudança paradigmática, e as ações e formas de organização presentes no contexto da sala de aula, permanecendo sob estruturas coerentes com o paradigma simplificador.

Após a coleta e análise dos dados, observamos que algumas questões merecem futuras investigações para ampliação e complementaridade dos resultados da pesquisa. Observa-se, por exemplo, que existe diálogo e reflexão entre autores de artigos científicos, ou seja, é comum a troca de conhecimento entre eles, a citação e a reapropriação de enunciados escritos nos artigos científicos dos anos anteriores e, em alguns casos, também em artigos escritos no mesmo ano. Seria importante, futuramente, investigar, nos elementos pós-textuais dos artigos, a frequência de citações das 12 revistas selecionadas para se ter uma ideia do nível de comunicação entre elas. A revista da ABEM é uma revista significativamente citada em artigos de outras revistas, quando o assunto é educação musical. Caberia também observar a relação entre os temas dos Encontros Nacionais da ABEM, as temáticas desenvolvidas nos artigos da ABEM daquele ano e a repercussão desses enunciados nos artigos científicos de outros periódicos e na comunidade da educação musical em geral, a fim de se ter mais indícios do processo de construção do conhecimento sobre educação musical na educação básica.

\section{Referências}

1. ÁLVARES, Sérgio Luís de Almeida. (mar. 2005) A educação musical curricular nas escolas regulares do Brasil: a dicotomia entre o direito e o fato. Revista da ABEM, Porto Alegre, v.12, p.57-64.

2. ARROYO, Margarete. (jun. 2002). Mundos musicais locais e educação musical. Em Pauta. Porto Alegre, v.13, n.20, p.95-122.

3. ARROYO, Margarete. (mar. 2004). Música na educação básica: situações e reações nesta fase pós-LDBEN/96. Revista da ABEM, Porto Alegre, v.10, p.29-34. 
AMUI, Gustavo Araújo; GUIMARÃES, Fernanda Albernaz do Nascimento (2016). Música na educação básica: referenciais teóricos de periódicos nacionais publicados entre 2000 e 2010. Per Musi. Ed. por Fausto Borém, Eduardo Rosse e Débora Borburema. Belo Horizonte: UFMG, n.34, p.89-112.

4. ARROYO, Margarete. (set. 2005). Música na Floresta do Lobo. Revista da ABEM, Porto Alegre, v.13, p.17-28, set.2005.

5. AZEVEDO, Maria C. de C. Cascelli de. (2009). Educação musical e cultura musical: diálogo entre o filme Escola de Rock e Bernard Charlot. Música em Contexto, Brasília, n.III, p.93-117.

6. BAKHTIN, Mikhail. (2003). Estética da criação verbal. 4. ed. São Paulo: Martins Fontes.

7. BARBOSA, Karla Jaber; FRANÇA, Maria Cecília Cavalieri. (set. 2009). Estudo comparativo entre a apreciação musical direcionada e não direcionada de crianças de sete a dez anos em escola regular. Revista da ABEM, Porto Alegre, v.22, p.7-18.

8. BARBOSA, Maria Flávia Silveira. (mar. 2007). Educação musical infantil: uma nova proposta. Claves, João Pessoa, n.3, p.74-82.

9. BEINEKE, Viviane. (2001). O conhecimento prático do professor: uma discussão sobre as orientações que guiam as práticas educativo-musicais de três professoras. Em Pauta, Porto Alegre, v.12, n.18/19, p.95-129.

10. BELLOCHIO, Cláudia Ribeiro. (mar. 2003). A formação profissional do educador musical: algumas apostas. Revista da ABEM, Porto Alegre, v.8, p.17-24.

11. BELLOCHIO, Claudia Ribeiro; BEINEKE, Viviane. (2007). A mobilização de conhecimentos práticos no estágio supervisionado: um estudo com estagiários de música da UFSM/RS e da UDESC/SC. Música Hodie, Goiânia, v.7, n.2, p.73-88.

12. BENEDETTI, Kátia Simone; KERR, Dorotea Machado. (2010). A Educação Musical sob a Perspectiva da Pedagogia Histórico-Crítica. Música Hodie, Goiânia, v.10, n.2, p.71-90.

13. BRASIL. (1971). Presidência da República. Lei no 5.692, de 11 de agosto de 1971. Fixa diretrizes e bases para o ensino de $1^{\circ}$ e $2^{\circ}$ graus, e dá outras providências. Brasília. Disponível em:http://www6.senado.gov.br/legislacao/ListaPublicacoes.action?id=102368 Acesso em: 15 maio 2013.

14. BRASIL. (1996). Presidência da República. Casa Civil. Subchefia para Assuntos Jurídicos. Lei no. 9.394, de 20 de dezembro de 1996. Estabelece as diretrizes e bases da educação nacional. Disponível em:

<http://www.planalto.gov.br/ccivil_03/Leis/L9394.htm>. Acesso em: 8 maio 2013.

15. BRASIL. (1997). Secretaria de Educação Fundamental. Parâmetros Curriculares Nacionais: Arte / Secretaria de Educação Fundamental. - Brasília: MEC/SEF. Disponível em: <http://portal.mec.gov.br/seb/arquivos/pdf/livro06.pdf> Acesso em: 3 jun. 2013. 
AMUI, Gustavo Araújo; GUIMARÃES, Fernanda Albernaz do Nascimento (2016). Música na educação básica: referenciais teóricos de periódicos nacionais publicados entre 2000 e 2010. Per Musi. Ed. por Fausto Borém, Eduardo Rosse e Débora Borburema. Belo Horizonte: UFMG, n.34, p.89-112.

16. BRASIL. Ministério da Educação e do Desporto. Secretaria de Educação Fundamental. Referencial Curricular Nacional para a Educação Infantil. Brasília, v. 2: MEC/SEF, 1998. Disponível em: < http://portal.mec.gov.br/seb/arquivos/pdf/volume2.pdf> Acesso em: 3 jun. 2013.

17. BRASIL. (2008). Presidência da República. Lei no 11.769, de 18 de agosto de 2008. Altera a Lei no 9.394, de 20 de dezembro de 1996, Lei de Diretrizes e Bases da Educação, para dispor sobre a obrigatoriedade do ensino da música na educação básica. Brasília. Disponível em: <http://www.planalto.gov.br/ccivil_03/_Ato20072010/2008/Lei/L11769.htm>. Acesso em: 8 maio 2013.

18. BUSTOS, María Angélica. (2007). Un itinerario reflexivo, semántico y didáctico, sobre interdisciplinariedad en Educación Musical: dos informes de investigación. Em Pauta, Porto Alegre, v.18, n.31, p.95-122.

19. CASTRO, Vanessa Weber de. (2009). A música nas escolas públicas estaduais da região metropolitana do Rio de Janeiro. Cadernos do Colóquio, Rio de Janeiro, v.10, n.1, p.134-142.

20. CERQUEIRA, Daniel Lemos. (2009). 0 arranjo como ferramenta pedagógica no ensino coletivo de piano. Música Hodie, Goiânia, v.9, n.1, p.129-140.

21. COSTA, Patrícia Soares Santos. (2008). Coro Juvenil - uma alternativa para a educação musical dos adolescentes. Cadernos do Colóquio, Rio de Janeiro, v.9, n.1. Disponível em:

<http://www.seer.unirio.br/index.php/coloquio/article/viewFile/226/216> Acesso em: 23 jan.2012.

22. COUTO, Ana Carolina Nunes; SANTOS, Israel Rodrigues Souza. (jun. 2009). Por que vamos ensinar Música na escola? Reflexões sobre conceitos, funções e valores da Educação Musical Escolar. Opus, Goiânia, v.15, n.1, p.110-125.

23. CUERVO, Luciane; PEDRINI, Juliana. (set. 2010). Flauteando e Criando: reflexões e experiências sobre criatividade na aula de música. Música na educação básica, Porto Alegre, v.2, n.2, p.48-61.

24. DANTAS, Andrea Stewart. (2001). 0 tamborim e seus devires na linguagem dos sambas de enredo. Revista da Abem, Porto Alegre, n.6, p.17-23.

25. DEL BEN, Luciana. (2001). A delimitação da educação musical como área de conhecimento: contribuições de uma investigação junto a três professoras de música do Ensino Fundamental. Em Pauta, Porto Alegre, v.12, n.18/19, p.65-93.

26. DEL BEN, Luciana. (2002). Práticas pedagógico-musicais escolares: concepções e ações de três professoras de Música do ensino fundamental. Opus, [S.l.], n.8.

Disponível em:

<http://www.anppom.com.br/opus/data/issues/archive/8/files/Ben/> Acesso em: 12 mar.2012. 
AMUI, Gustavo Araújo; GUIMARÃES, Fernanda Albernaz do Nascimento (2016). Música na educação básica: referenciais teóricos de periódicos nacionais publicados entre 2000 e 2010. Per Musi. Ed. por Fausto Borém, Eduardo Rosse e Débora Borburema. Belo Horizonte: UFMG, n.34, p.89-112.

27. DEL BEN, Luciana. (2005). Um estudo com escolas da rede estadual de educação básica de Porto Alegre/RS: subsídios para a elaboração de políticas de educação musical. Música Hodie, Goiânia, v.5, n.2, p.65-89.

28. DUARTE. Mônica de Almeida. (2001). Contribuições da retórica para o estudo da representação de 'música' por alunos e professores de escolas de ensino fundamental. Cadernos do Colóquio. Rio de Janeiro, p.128-141.

29. DUARTE, Mônica de Almeida; MAZZOTTI, Tarso Bonilha. (set. 2002). Sobre os processos de negociação dos sentidos da música na escola. Revista da ABEM, Porto Alegre, v.7, p.31-40.

30. FERREIRA, Juliana Grassi Pinto. (2007). A influência da performance vocal no desenvolvimento das funções cognitivas e comunicativas da linguagem oral da criança. Per Musi, Belo Horizonte, n.15, p.72-77.

31. FERNANDES, José Nunes. (2001). Caracterização da didática musical. Debates, Rio de Janeiro, n.4, p.49-74.

32. FERNANDES, José Nunes. (mar. 2004). Normatização, estrutura e organização do ensino da música nas escolas de educação básica do Brasil: LDBEN/96, PCN e currículos oficiais em questão. Revista da ABEM, Porto Alegre, v.10, p.75-87.

33. FERNANDES, José Nunes. (mar. 2005). Educação musical de jovens e adultos na escola regular: políticas, práticas e desafios. Revista da ABEM, Porto Alegre, v.12, p.35-41.

34. FRANÇA, Cecília Cavalieri. (set. 2006). Do discurso utópico ao deliberativo: fundamentos, currículo e formação docente para o ensino de música na escola regular. Revista da ABEM, Porto Alegre, v.15, p.67-79.

35. FRANÇA, Cecília Cavalieri. (set. 2010) Dizer o "dizível”: avaliação sistêmica em música na escola regular. Revista da ABEM, Porto Alegre, v.24, p.94-106.

36. FUCCI AMATO, Rita de Cássia. (2006). Breve retrospectiva histórica e desafios do ensino de música na educação básica brasileira. Opus, Campinas, SP, v.12, p.144-165.

37. FUCCI AMATO, Rita de Cássia; CARLINI, Marcela Maia. (2008). A saúde vocal dos educadores musicais: um estudo comparativo com docentes atuantes na educação infantil e no ensino fundamental. Música Hodie, Goiânia, v.8, n.2, p.107-125.

38. GOMES, Celson Henrique Sousa. (mar. 2003). Formação e atuação de músicos de rua: possibilidades de atuação e de caminhos formativos. Revista da ABEM, Porto Alegre, v.8, p.25-28.

39. LIMA, Sonia Albano; TRAJANO, Alexandre. (2008). A perspectiva de ensino artístico projetada por H. Gardner e os Parâmetros Curriculares Nacionais (Arte) do ensino fundamental. Música Hodie. Goiânia, v.8, n.2, p.127-143. 
AMUI, Gustavo Araújo; GUIMARÃES, Fernanda Albernaz do Nascimento (2016). Música na educação básica: referenciais teóricos de periódicos nacionais publicados entre 2000 e 2010. Per Musi. Ed. por Fausto Borém, Eduardo Rosse e Débora Borburema. Belo Horizonte: UFMG, n.34, p.89-112.

40. MATEIRO, Teresa. (jun. 2003). El debate sobre el practicum y su relación em la formación Del profesorado de música. Em Pauta. Porto Alegre, v.14, n.22, p.5-34.

41. MORIN, Edgar. (2007). Introdução ao pensamento complexo. 3. ed. Porto Alegre: Sulina.

42. MORIN, Edgar. (2008a). A Cabeça Bem-Feita: repensar a reforma, reformar o pensamento. 15. ed. Rio de Janeiro: Bertrand Brasil.

43. MORIN, Edgar. (2008b). 0 Método 4. 4. ed. Porto Alegre: Sulina.

44. MORIN, Edgar. (2010). Ciência com consciência. 14. ed. Rio de Janeiro: Bertrand Brasil.

45. OLIVEIRA, Alda. (2006). Educação musical e identidade: mobilizando o poder da cultura para uma formação mais musical e um mundo mais humano. Claves, João Pessoa, n.2, p.31-45.

46. OLIVEIRA, Mário André W. et al. (2012). Produção científica sobre educação musical escolar: uma análise das referências de artigos da Revista da ABEM. In: XXII Congresso da ANPPOM, 2012, João Pessoa-PB. Anais do XXII Congresso da ANPPOM. João Pessoa: UFPB, p.1879-1886.

47. PENNA, Maura. (set. 2002). Professores de música nas escolas públicas de ensino fundamental e médio: uma ausência significativa. Revista da ABEM, Porto Alegre, v.7, p.7-19.

48. PENNA, Maura. (set. 2003). Apre(e)ndendo músicas: na vida e nas escolas.

Revista da ABEM, Porto Alegre, v.9, p.71-79.

49. PENNA, Maura. (mar. 2004). A dupla dimensão da política educacional e a música na escola: I - analisando a legislação e termos normativos. Revista da ABEM, Porto Alegre, v.10, p.19-28.

50. PENNA, Maura. (mar. 2008). Caminhos para a conquista de espaços para a música na escola: uma discussão em aberto. Revista da ABEM, Porto Alegre, v.19, p.57-64.

51. QUEIROZ, Luís Ricardo Silva; MARINHO, Vanildo Mousinho. (set. 2007). Educação musical nas escolas de educação básica: caminhos possíveis para a atuação de professores não especialistas. Revista da ABEM, Porto Alegre, n.17, p.69-76.

52. QUEIROZ, Luís Ricardo Silva; MARINHO, Vanildo Mousinho. (2010). A formação continuada de professores de música no contexto da educação nacional. Ictus, [S.l.], v.11, n.2, p.100-119.

53. RODRIGUES, Rosângela Hammes. (2004). Análise de gêneros do discurso na teoria bakhtiniana: algumas questões teóricas e metodológicas. Linguagem em (Dis)curso. Universidade do Sul de Santa Catarina. Tubarão, v.4, n.2, p.415-440. 
AMUI, Gustavo Araújo; GUIMARÃES, Fernanda Albernaz do Nascimento (2016). Música na educação básica: referenciais teóricos de periódicos nacionais publicados entre 2000 e 2010. Per Musi. Ed. por Fausto Borém, Eduardo Rosse e Débora Borburema. Belo Horizonte: UFMG, n.34, p.89-112.

54. SANTOS, Akiko. (2003). Didática sob a ótica do pensamento complexo. Porto Alegre: Sulina.

55. SANTOS, Claudia Eboli Corrêa dos. (2006). Um olhar sobre as diferenças: cidadania, música e a escola inclusiva. Cadernos do Colóquio, Rio de Janeiro, v.8, n.1. Disponível em:

<http://www.seer.unirio.br/index.php/coloquio/article/viewFile/122/86> Acesso em: 15 fev. 2012.

56. SANTOS, Regina Marcia Simão. (2001). Jaques-Dalcroze, avaliador da instituição escolar: em que se pode reconhecer Dalcroze um século depois? Debates, Rio de Janeiro, n.4, p.7-48.

57. SEBBEN, Egon Eduardo; SUBTIL, Maria José. (mar. 2010). Concepções de adolescentes de $8^{a}$ série sobre música: possíveis implicações para a implementação das práticas musicais na escola. Revista da ABEM, Porto Alegre, v.23, p.48-57.

58. SILVA, Helena Lopes da. (2006). Gênero, adolescência e música: um estudo de caso no espaço escolar. Em Pauta, Porto Alegre, v.17, n.28, p.71-92.

59. SOUZA, Jusamara et al. (2003). Práticas de aprendizagem musical em três bandas de rock. Per Musi, Belo Horizonte, v.7, p.68-75.

60. SOUZA, Cássia Virgínia Coelho de. (2004). Educação Musical a Distância para professores das séries iniciais do ensino fundamental. Em Pauta. Porto Alegre, v.15, n.24, p.107-142.

61. SOUZA, Fernanda de. (2008). O brinquedo popular e o ensino de música na escola. Revista da ABEM, Porto Alegre, v.19, p.75-81.

62. SPANAVELLO, Caroline Silveira; BELLOCHIO, Cláudia Ribeiro. (mar. 2005). Educação musical nos anos iniciais do ensino fundamental: analisando as práticas educativas de professores unidocentes. Revista da ABEM, Porto Alegre, v.12, p.8998.

63. TEZZA, Cristovão. (1988). Discurso poético e discurso romanesco na teoria de Bakhtin. In: FARACO, Carlos Alberto. Uma introdução a Bakhtin. Curitiba: Hatier. p.51-71.

64. VIEIRA, Edna Aparecida Costa et al. (2004). 0 papel do fazer musical no ensino regular.Música Hodie, Goiânia, v.4, n.2, p.39-51.

65. WEICHSELBAUM, Anete Susana. (2002). Tendências da educação e do currículo no final do século XX, metáforas utilizadas e conceito de mapa na obra de Keith Swanwick. Cadernos do Colóquio, Rio de Janeiro, v.5, n.1, p.44-61. 
AMUI, Gustavo Araújo; GUIMARÃES, Fernanda Albernaz do Nascimento (2016). Música na educação básica: referenciais teóricos de periódicos nacionais publicados entre 2000 e 2010. Per Musi. Ed. por Fausto Borém, Eduardo Rosse e Débora Borburema. Belo Horizonte: UFMG, n.34, p.89-112.

Nota sobre os autores

Gustavo Araújo Amui é Mestre em Música pela UFG (2013), possui graduação em Educação Musical - licenciatura em violão - também pela Universidade Federal de Goiás (2010). Atuou como professor efetivo de música na rede estadual de ensino de $2010 \mathrm{a}$ 2015. Entre os anos de 2010 a 2014 foi membro da equipe de música no Centro de Estudo e Pesquisa Ciranda da Arte, onde desenvolveu e elaborou diretrizes e planejamentos para o ensino coletivo de violão na educação básica do estado de Goiás. Desenvolveu pesquisa de mestrado com enfoque na educação musical no campo da educação básica, sob a orientação da Prof ${ }^{\mathrm{a}}$. Dra . Fernanda Albernaz do Nascimento Guimarães. Atualmente é professor efetivo de música no Instituto Federal de Mato Grosso (IFMT).

Fernanda Albernaz do Nascimento Guimarães é Professora Associada da Escola de Música e Artes Cênicas da Universidade Federal de Goiás (UFG), onde atua nos cursos de graduação Música Bacharelado, Música Licenciatura e no Programa de PósGraduação em Música nas linhas de pesquisa Música, Educação e Saúde; Música, Cultura e Sociedade. É Líder do Diretório de Pesquisa- CNPq - Arte, Educação, Cultura. Seus resultados de pesquisa incluem artigos sobre música e suas interfaces (educação musical, musicologia, musicoterapia e cultura) em periódicos. Atualmente é avaliadora de cursos de graduação e instituições de ensino superior do Instituto Nacional de Estudos e Pesquisas Educacionais Anísio Teixeira (INEP). 